\title{
A (IN) CONSTITUCIONALIDADE DA MEDIDA DE SEGURANÇA: E A SUA INDETERMINAÇÃO TEMPORAL ENTRE 1940 A 2015
}

\author{
Cleyton Heleno Pereira da Silva, Danielle Yurie Moura da Silva \\ Universidade do Oeste Paulista - UNOESTE. Curso de Direito, Presidente Prudente, SP.
}

\section{RESUMO}

A presente pesquisa tem por finalidade refletir sobre acerca do lapso temporal da medida de segurança. Visto que a medida de segurança preconizada no artigo 97 do código penal, afirma que tal instituto possui prazo indeterminado, isto é, existe a possibilidade de a medida protelar até que seja cessada a periculosidade do individuo. Por outro lado verifica-se que nossa magna carta veda a existência de pena perpetua, Ante as afirmações resta a mais incessante divergência doutrinaria, ou seja, quanto à inconstitucionalidade ou não da medida de segurança imposta a um individuou, sem que seja condicionado um prazo para sua extinção. Deste modo realizando uma breve analise reflexiva dos diversos posicionamentos, assim como o recente entendimento do Superior tribunal de justiça e a edição da súmula 527 de 2015, onde estipula parâmetro executório, verifica-se que a aplicação de tal medida ao longo dos anos desde a entrada em vigor do código penal de 1940, aplicou-se de forma inconstitucional, A metodologia adotada consiste no método hipotéticodedutivo, através de pesquisa bibliográfica, com a utilização de doutrina, jurisprudência e artigos eletrônicos entre outros. Conclui-se que a medida de segurança hoje não é mais inconstitucional.

Palavras chaves: Medida de segurança - execução penal - pena - caráter perpetuo - (in) constitucionalidade - direitos fundamentais.

\section{THE (IN) CONSTITUTIONALITY OF THE SAFETY MEASURE: AND ITS TEMPORARY INDETERMINATION BETWEEN 1940 TO 2015}

\begin{abstract}
The present research is intended to reflect on the time lapse of the security measure. Since the security measure recommended in Article 97 of the Criminal Code states that such an institute has an indefinite term, that is, there is a possibility that the measure will delay until the dangerousness of the individual is terminated. On the other hand, it is verified that our great letter forbids the existence of a perpetual sentence. In the face of the affirmations there remains the most incessant doctrinal divergence, that is, as to the unconstitutionality or not of the security measure imposed on an individual, without being conditioned a term to its extinction. In this way, carrying out a brief reflective analysis of the various positions, as well as the recent understanding of the Superior Court of Justice and the edition of the summary 527 of 2015, where it establishes an enforceable parameter, it is verified that the application of such measure over the years since The adopted methodology consists of the hypothetical-deductive method, through bibliographical research, with the use of doctrine, jurisprudence and electronic articles, among others. It is concluded that the security measure today is no longer unconstitutional.
\end{abstract}

Keywords: Security measure - penal execution - penalty - perpetual character - (in) constitutionality - fundamental rights. 


\section{INTRODUÇÃO}

A medida de segurança hoje é um assunto pouco abordado entre os juristas, no entanto já foi tema de grande discussão doutrinaria e jurisprudencial. Assim buscaremos no decorrer desta pesquisa refletir e compreender sobre o tema abordado. Buscando realizar uma analise crítico reflexiva em relação à durabilidade indeterminada do prazo de tal instituto até o ano de 2015.

Anteriormente a edição da Súmula do Superior Tribunal de Justiça, verifica-se que era aplicado o previsto no artigo $97, \S 1$ 10 do código penal.

Ante o exposto, nota-se que a internação de individuo com deficiência, ou transtornos mentais que praticam condutas criminosas e são submetidos a medida de segurança, podem permanecer a vida inteira em tratamento ambulatorial. Partindo da premissa de que a medida de segurança possui natureza de pena, sanção aplicada aos agentes inimputáveis praticantes de condutas previstas como crimes e a sua indeterminação temporal de durabilidade da medida, que buscaremos através dessa pesquisa verificar a in-constitucionalidade do instituto.

Em síntese o tema já foi consuetudinariamente discutido devido trata-se de uma questão extremamente polémica, o que merece uma atenção especial devido sua relevância, visto existir inúmeros casos onde o indivíduo encontra-se nessa situação. Temos como exemplo o caso do índio Febrônio, que submetido ao instituto de medida de segurança aos 34 anos de idade, ingressando no Manicômio Judiciário do Rio de Janeiro permanecendo lá por 55 anos até a data de seu falecimento, em 1984. (GUTMAN, 2010)

Frise-se, portanto, que o principal objetivo desta pesquisa é refletir acerca do instituto em apreço, podendo vir a contribuir e despertar o interesse para novas pesquisas visto tratar-se de um tema extremamente relevante para as ciências jurídicas e áreas afins.

\section{DA MEDIDA DE SEGURANÇA}

O código penal de 1940 nos traz nos artigos 96 a 99 preve o instituto da medida de segurança, e sua execução encontram-se nos artigo 171 a 179 da Lei de execução penal. A medida de segurança é um instituto utilizado para punir um determinado individuo inimputável ou semiinimputavel, no qual seja autor de um fato tipificado como crime, impedindo que volte a praticar outro ato injusto, a medida de segurança possui caráter preventivo proporcionando um tratamento adequado.

Assim Leciona Nucci (2011, p. 576) conceitua medida de segurança como:

[...] Uma forma de sanção penal, com caráter preventivo e curativo, visando a evitar que o autor de um fato havido como infração penal, inimputável ou semi-inimputavel, mostrando periculosidade, torne a cometer outro injusto e receba tratamento adequado [...]. (NUCCl, 2011, p. 576).

Afirma Nucci (2011) que seguindo o mesmo raciocínio ao conceito apresentado se tem o entendimento de Pierangeli e Zaffaroni, no qual compreende que a medida de segurança trata-se de uma espécie de sanção penal, visto que ao se tirar a liberdade de um indivíduo, em virtude de uma conduta por ele praticada, na verdade o que existe é uma sanção penal, sendo este o entendimento majoritário.(PIERAGELI; ZAFFARONI apud NUCCI, 2011, p.576).

No mesmo sentido leciona Estefam e Gonçalves (2016) que a medida de segurança é uma:

Espécie de sanção penal, de caráter preventivo, fundada na periculosidade do agente, aplicada pelo juiz da sentença, por prazo indeterminado, aos inimputáveis e eventualmente aos semi-imputaveis, a fim de evitar que tornem a delinquir. (ESTEFAM; GONÇALVES, 2016, p. 661).

Uma vez compreendido os conceitos acima aludidos, torna-se possível notar que a medida de segurança aplica-se àquelas pessoas que cometem delito e que possuem doenças mentais, verifica-se que a medida de segurança possui natureza de pena com caráter preventivo, a fim de 
evitar que o inimputável ou semi-imputaveis volte a realizar a pratica de conduta tipificada como crime.

\section{APLICAÇÃO DA MEDIDA DE SEGURANÇA E SEUS PRESSUPOSTOS}

Nota-se que à medida de segurança é um instituto aplicado a os delinquentes, no qual encontra-se em condição de inimputabilidade ou semi-imputabilidade, no entanto, para que haja a aplicação deste instituto, podendo o juiz ao proferir a sentença, determinando a aplicação da medida de segurança deverá 'ser observado alguns pressupostos necessários para tal medida.

Nelson Hungria (1956) em sua obra clássica "comentários ao código penal", já previa a existência dos pressupostos para a aplicação da medida de segurança:

São dois os pressupostos da aplicação da medida de segurança: á pratica de fato previsto como crime (salvo as hipóteses do paragrafo único do artigo ora comentado) e a periculosidade do agente. (HUNGRIA, 1956, P. 34).

Do mesmo modo, leciona Damásio de Jesus (2011, p. 591): “A aplicação da medida de segurança pressupõe: a pratica de fato descrito como crime; e a periculosidade do sujeito".

Verifica-se que acerca da aplicação da medida de segurança e seus pressupostos a doutrina e pacífica e entende que para a aplicação da medida de segurança a determinado indivíduo é necessário que este tenha praticado conduta tipificada como crime cominado com a periculosidade do agente.

\section{PRAZO DA MEDIDA DE SEGURANÇA}

Ao verificar-se o prazo de duração do instituto da medida de segurança, preliminarmente e necessário destacar que existem quatro correntes a respeito do assunto conforme assevera Nucci (2011). A primeira tem duração indefinida, nos termos do disposto no artigo 97, §1 do código penal; a segunda entende que deve ter a mesma duração da pena privativa de liberdade aplicada. O sentenciado cumpre internado o restante da pena aplicada; a terceira entende que a duração máxima de trinta anos, limite fixado para pena privativa de liberdade; e a última não menos importante entende que a duração do máximo em abstrato previsto como pena para o delito que deu origem a medida de segurança. (NUCCl, 2011, p. 581-582).

O Código Penal, traz a previsão legal de que a medida de segurança deve perdurar no tempo ate que seja cessada a periculosidade do individuo, tendo este prazo indeterminado segundo prevê o artigo 97, §1을

Art. 97 - (in omissis)

$\S 1$ - - A internação, ou tratamento ambulatorial, será por tempo indeterminado, perdurando enquanto não for averiguada, mediante perícia médica, a cessação de periculosidade. O prazo mínimo deverá ser de 1 (um) a 3 (três) anos.(BRASIL,1940).

A lei de execução penal encarregou-se de trazer o Titulo VI que aborda exclusivamente a figura da medida de segurança na fase de execução, no entanto, a legislação é omissa quanto ao limite máximo que tal medida pode durar.

A Constituição veda a pena de caráter perpétua, assim a Suprema Corte em virtude a omissão do legislador passou a entender que o prazo máximo de aplicação da medida de segurança é de 30 anos conforme previsto no artigo 75 do código penal aplicando esse limite em respeito à vedação da prisão perpetua preconizada no artigo 5ㅇ, inciso XLVII, CF. (ESTEFAM; GONÇALVES, 2016, p. 664).

Em contra partida, a interpretação do Superior Tribunal de Justiça, entende que não pode ser imposta medida de segurança com lapso temporal superior ao máximo previsto em abstrato no tipo penal do ato praticado, editando assim a Súmula 527 sendo aprovada em 13 de maio de 2015. (ESTEFAM; GONÇALVES, 2016, p. 663) 
Súmula 527-STJ: O tempo de duração da medida de segurança não deve ultrapassar o limite máximo da pena abstratamente cominada ao delito praticado. STJ. 3a Seção. (SUPERIOR TRIBUNAL DE JUSTIÇA, 2015).

Diante as breves considerações acerca da duração da medida de segurança, é possível afirma que hoje o entendimento predominante encontra-se respaldo no posicionamento do Superior Tribunal de Justiça, onde notadamente assevera que a medida de segurança não pode ultrapassar o limite máximo da pena em abstrato do delito praticado, em respeito à vedação da pena perpetua.

\section{VEDAÇÃO CONSTITUCIONAL ÀS PENAS PERPÉTUAS NO BRASIL}

A ideia de pena perpétua é trazida e se dá pelo ato de retirar de um indivíduo o seu direito de liberdade cerceado assim o seu direito de ir e vir até que este venha a falecer, ou seja, sua pena perdurara no tempo até o exato momento de sua morte.

Em muitos países a ideia de prisão perpetua, é considerada uma condição desumana ferindo o princípio da dignidade da pessoa humana, pois uma vez que o condenado será retirado do convívio social, será também retirado dele a esperança de reaver a sua liberdade, conforme leciona Aníbal Bruno:

A prisão perpétua é uma pena de segurança. A sociedade defende-se, afastando definitivamente do seu seio o homem que gravemente delinquiu. Mas é uma pena cruel e injusta. Priva o condenado não só da liberdade, mas da esperança da liberdade, que poderia encorajá-lo e tornar-lhe suportável a servidão penal. (BRUNO apud MENEZES, 2009).

No Brasil a pena de caráter perpétuo, encontra-se completamente impossibilitada de adentrar ao sistema penal, por previsão expressa da nossa Magna Carta: Art. 5o, XLVII, "b" - não haverá penas: de caráter perpétuo.

O entendimento da doutrina é praticamente unânime, ao entender que essa modalidade de pena é totalmente negativa, não trazendo benefício algum para a sociedade tampouco ao indivíduo apenado.

Deste modo, a fim de garantir tal preceito fundamental o legislado dispôs no art. 75 do Código Penal brasileiro que as penas privativas de liberdades não podem superar 30 anos, tempo máximo de cumprimento. No entanto não foi atentado para o lapso temporal que pode a medida de segurança durar visto que o Código Penal afirma que a medida deve durar por prazo indeterminado sendo extinta a periculosidade do indivíduo, deste modo indaga-se sobre a constitucionalidade da medida de segurança.

\section{CARACTERIZAÇÃO DE INCONSTITUCIONALIDADE ADVINDA DE PENA PERPÉTUA}

A inconstitucionalidade de uma lei, de instituto, ou até mesmo de uma norma constitucional está atrelada a incongruência com a própria constituição.

Deste modo, conceitua Lúcio Bittencourt (1997, p.132) que, "a inconstitucionalidade é um estado - estado de conflito entre uma lei e a Constituição".

No mesmo sentido leciona José Afonso da Silva, que a inconstitucionalidade, está atrelada a conformidade com os ditames constitucionais, a qual não se satisfaz apenas com a atuação positiva de acordo com a Constituição, mas ainda com o não omitir a aplicação de normas constitucionais quando a Constituição assim o determina. (SILVA, 1994, p.48)

Para Darcy Azambuja (1988, p. 172) inconstitucionalidade é toda a lei ordinária que, no todo ou em parte, contrarie ou transgrida um preceito da Constituição, diz-se inconstitucional.

Gomes Canotilho lembra o conceito clássico, no qual nota-se, haver sido referido por todos: inconstitucional é toda lei que viola os preceitos constitucionais. (CANOTILHO, 1998, p. 878) 
A doutrina mostra-se pacífica ao conceituar inconstitucionalidade como uma norma que desrespeita, pois entra em conflito com aquilo que preconiza a própria constituição.

Após refletirmos sobre inconstitucionalidade, assim como o instituto da medida de segurança, seus pressupostos e aplicação, assim como seu prazo e a vedação das penas de caráter perpetuo, indaga-se. A Medida de segurança prevista no artigo $97 \S 1$ 으 do código penal trata-se de uma norma constitucional?

Nota-se que a aplicação da medida de segurança ao longo dos anos desde a promulgação do Código Penal em 1940 até a edição da sumula 527 do superior tribunal de justiça em 2015, mostrava-se confrontar preceitos fundamentais preconizados em nossa Magna Carta.

Ao analisarmos o caráter da medida de segurança e ao verificar que esta possui a mesmo natureza de pena tendo em vista tratar-se de uma modalidade de sanção penal aplicada aos infratores inimputáveis, tanto nota-se que esta medida encontra-se normatizada na lei de execução penal em seu artigo 75 a 79.

A demais nota-se que tais normas tanto as do Código Penal, que não limita o prazo de duração da medida de segurança quanto à própria lei de execução penal ao se omitir sobre a indeterminação do prazo, colidem com o previsto na constituição federal de 1988.

Deste modo, entende-se que tal medida não deveria ter sido aplicada até que fosse determinado um prazo para seu termino como foi realizado no ano de 2015 pelo Superior Tribunal de Justiça.

Neste sentido vale ressaltar o posicionamento de Nelson de Souza Sampaio onde afirma que:

Considera inaplicável uma norma do constituinte originário quando em flagrante e insanável conflito com outra norma do mesmo texto constitucional reputada de maior peso ou de mais alto valor. (SAMPAIO apud RAMOS, 1994, p.83).

Haja vista, que as normas previstas na constituição, no código penal assim como a Lei de exceção penal, mostram-se totalmente incongruente visto não observar o previsto em nossa norma maior.

\section{CONSIDERAÇÕES FINAIS}

Diante todo o exposto, verificou-se que a medida de segurança e pena são sinônimos, embora possuam finalidades opostas, visto que aquela possui caráter preventivo, evitando que um indivíduo inimputável torne a praticar condutas criminosas devido sua condição. Enquanto a outra possui obrigatoriamente a finalidade de punir o individuo praticante de condutas tipificadas como crime.

Com relação à medida de segurança existem diversos posicionamentos Há aqueles que apoiam o artigo $97 \S 1^{\circ}$ do $C P$, visto que o Estado assumiu para si a incumbência e responsabilidade pela segurança social, não poderia libertar um agente que não encontra-se sanada sua periculosidade podendo voltar a delinquir.

No entanto, alguns acreditam que essa forma de indeterminação temporal das medidas de segurança estaria ferindo a Constituição Federal visto que mesma veda a aplicação da prisão perpétua, não podendo o Estado juiz restringir a liberdade de um individuo por tempo indeterminado.

Verificou-se ainda, que embora o Código Penal não fizesse menção em sua redação ao prazo máximo para aplicação da medida de segurança.

No entanto, foi possível refletir sobre os mais divergentes posicionamento, existentes entre o Supremo Tribunal Federal e Superior Tribunal de Justiça, no que diz respeito ao prazo de durabilidade da medida, notoriamente é possível afirmar que, hoje o entendimento mais benéfico ao indivíduo no qual encontra-se sob a égide da aplicação do instituto da medida de segurança, é o posicionamento adotado pelo Superior Tribunal de Justiça, onde assevera que a medida de 
segurança não pode ultrapassar o limite máximo da pena em abstrato do delito praticado, em respeito à vedação da pena perpetua, preferindo limitar as medidas de segurança por entenderem que a não fixação de prazos é inconstitucional.

Deste modo, conclui-se que a medida de segurança ao longo dos anos desde a promulgação do código penal em 1940 até a edição da Súmula 527 do Superior Tribunal de Justiça em 2015, confrontava preceitos fundamentais preconizados em nossa Magna Carta, sendo assim entende-se que todas as medidas de segurança aplicadas neste período de tempo foram impostas de forma inconstitucional, por não preverem um prazo máximo para sua aplicação caracterizando assim uma sanção penal de caráter perpétuo, o que nossa Constituição Federal em seu artigo 5o inciso, XLVII expressamente veda, ou seja, não se admite penas de caráter perpetuo.

Assim vale ressaltar que, a edição da sumula 527 do Superior Tribunal de Justiça à medida de segurança passou a ser considerada plenamente constitucional visto que o mesmo delimitou prazo máximo para a aplicação da medida de segurança.

\section{REFERÊNCIAS}

AZAMBUJA, Darcy. Teoria geral do estado. 27. ed. Rio de Janeiro: Globo, 1988, p.172.

BITTENCOURT, C. A. Lúcio. O controle jurisdicional da constitucionalidade das leis. Atualizado por José Aguiar Dias. Brasília: Ministério da Justiça, 1997, p.132.

BRASIL, Republica Federativa do. Constituição federal de 1988. Promulgada em 5 de outubro de 1988. Disponível em http://www.planalto.gov.br/ccivil_03/constituicao/constituicaocompilado.htm> acesso em 13 maio 2018.

BRASIL, Republica Federativa do. Código penal de 1940. Promulgada em 7 de dezembro de 1940. Disponível em <http://www.planalto.gov.br/ccivil_03/decreto-lei/Del3689.htm> acesso em 13 maio 2018.

BRASIL, Superior Tribunal de Justiça. Medida de segurança. Sumula 527, aprovada em 18 Maio 2015. Disponível em:< http://www.stj.jus.br/SCON/sumanot/toc.jsp\#TIT1TEMA0>. Acesso em: 11 Maio 2018.

CANOTILHO, José J. G. Direito constitucional e teoria da constituição. 3. ed. Coimbra: Livraria Almedina, 1998, p. 878.

JESUS, Damásio de. Direito penal: parte geral. 32 ed. São Paulo: Saraiva 2011, p. 591.

ESTEFAM, André; GONÇALVES, Victor Eduardo Rios; coordenador, LENZA, Pedro. Direito penal esquematizado: parte geral. 5 ed. São Paulo: Saraiva, 2016, p. 661

GUTMAN, Guilherme. Febronio, Blaise \& Heitor. Pathos, violência e poder. Revista Latinoamericana de Psicopatologia Fundamental. vol.13 no. 2 São Paulo Jun. 2010. Disponível em: < http://www.scielo.br/scielo.php?script=sci_arttext\&pid=S1415-47142010000200002 >. Acessado em: 13 maio de 2018

HUNGRIA, Nelson. Comentários ao código penal: Decreto lei n22846 de 07 de dezembro de 1940. 3 ed. V.3. Rio de Janeiro: Forense, 1956, p. 34. 
MENEZES, Fabio Victor de Aguiar. A pena de prisão perpétua e o Tribunal Penal Internacional: Aspectos constitucionais. Âmbito Jurídico, Rio Grande, set. 2009. Disponível em:

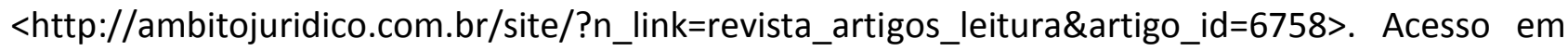
maio 2018.

NUCCl, Guilherme de Souza. Manual de direito penal: parte geral: parte especial. 7 ed. São Paulo: Revista dos Tribunais, 2011, p. 576

RAMOS, Elival da Silva. A inconstitucionalidade das leis: Vicio e sanção. São Paulo: Saraiva 1994, p.61-83

SILVA, José Afonso da. Curso de direito constitucional positivo. 9. ed. São Paulo: Malheiros, 1994, p.48. 